\title{
Reality and Dilemma Analysis of Civil Servants' Properties Declaration System in China
}

\author{
Xiong Zenan \\ Wuhan University of Technology, Wuhan, P.R.China, 430070
}

(E-mail: 191944997@qq.com)

\begin{abstract}
At present, the corruption in civil servants of China is in high-risk situation, which has seriously hampered the economic development and has damaged people's benefits. And the situation of struggling against corruption is very severe. The civil servants' properties declaration system, which includes declaration, registration and publication of family property, is recognized as one of the most effective anti-corruption system by the world and has been honored as the "Sunshine Act". The system can be used to prevent corruption, maintain social stability by supervising the properties of civil servants and restraining their individual behaviors. By using literature research method and comparative research method, this paper analyzes the reality of the official properties declaration system of China and expounds the necessity of further improvement of it, aiming to provide some suggestions for the official properties declaration system that is trapped in dilemma.
\end{abstract}

Key words: Civil servant; Properties declaration system; Operation status quo; Remedies

\section{Introduction to Civil Servants' Properties Declaration System}

\subsection{Background and significance of the article}

Corruption, which is referred to as "Cancer of Politics", has troubled governments around the world. Government's credibility and authority has suffered great damages due to the continuous increasing of the corruption of civil servants. "All powerful people are liable to abuse power, and this is an eternal unchanging experience. The powerful people will not stop using the power until extend to the boundaries of it."[1] So it is very necessary for the society to supervise over the power and the powerful people. China has reinforced the punishments for civil servants' corruption and a large number of high-ranking officials are punished these years. Indeed, these measures have a deterrent effect on the corruption. However, such actions are palliatives because the mechanism of corruption prevention is still imperfect. The "Sunshine Act", which was originated from Sweden, has been adopted as a powerful weapon of overwhelming corruption by most countries in the world. Civil servants' properties declaration system is a legal system that civil servants report individuals and their families' properties (such as quantity, resource and expenditure) to the relevant managing authorities under the statutory deadline and way, and accept supervision and inspection from relevant authorities based on the relevant state laws. China is a socialist country, the people's democratic politics shall be supervised by the people who are masters of the country, and the people wield the power to administer the country. Objectively, the development of democratic politics is closely related to the transparency of politics. The implementation of the civil servants' properties declaration system makes people have a wider range of 'right to know', which is also important to the stabilization of a nation. The civil servants' properties declaration system was established in 1995 in China and it is of great significance in the process of anti-corruption. However, it cannot be effectively carried out because of the obstacles in the implementation process, and it needs further improvement in the practice.

\subsection{Literature review}

There are many domestic researchers devote themselves to the study of civil servants' properties declaration system. Hu Xiaofeng investigated the present situation and problems of the present civil servants' properties declaration system in his article "The Study about Legislation of Civil Servants' Properties Declaration System", and provided suggestions to the improvement of the system's legislation. Gao Yifei illustrated officials' right of privacy and citizens' 'right to know' in his work 
“Officials' Properties Declaration Should be Legislated". Another two prominent researchers are Wang Minggao and Liu Mingbo, they lucubrated the properties declaration in their works in an objective way. In 1883, UK promulgated "the Act of Purify Election and Prevent Corruption", and it created a precedent for the construction of the properties declaration system. In the 1980s, Thailand, France, Germany, Singapore, South Korea and Russia etc also established civil servants' personal assets declaration system. Properties declaration system has made positive achievements in many countries, and it has become a sharp weapon for the curb of corruption from the source. In recent years, foreign scholars pay more attention to the moral effects of property declaration on political construction. Zimmerman•Joseph evaluated how the government effectively regulated the civil servants' moral behaviors in his article "Control Unethical Behaviors of the Government". In order to prevent corruption, $\mathrm{F} \cdot \mathrm{F} \cdot$ Ridley suggested that states should enact special laws to restrain civil servants in the article "Regulate the Personal Interests of Civil Servants".

\section{Analysis of Chinese Civil Servants' Properties Declaration System’ s Present Situation}

\subsection{Legislative status quo}

Since the reform and opening-up, civil servants' properties declaration system was gradually introduced into China. The system includes two aspects: the central government level and the local government level.

From the central government level, Ministry of Supervision and Bureau of Legislation drafted the Provisions of Reporting the State Administrative Staff's Assets and Income in 1988. The draft for the establishment of the system presented the concrete plan and stipulated the provisions of relevant matters and terms. This is the first draft of properties declaration system in history, and it marks the civil servants' properties declaration system has been put forward formally in our country. This draft had a far-reaching influence on the following construction of civil servants' properties declaration system and it also raised the curtain on the system in China. In 1994, the Standing Committee of the National People's Congress listed the properties declaration law into legislation plan in the Standing Committee of the Eighth National People's Congress, but it failed to enter into the legislative process. On April 20, 1995, General Office of the Central Committee and General Office of the State Council jointly issued Provisions of Reporting Leading Cadres' income at or above the County Level in the Party and Government Organs. This is the first regulation which requires party and government leading cadres to declare income and accept supervision. It stipulates the purpose, subjects of declaration, scope of declaration, time of declaration, accepting institution, violation responsibilities as well as commencement date and it constructs the basic framework of properties declaration system in China. Although there are some problems such as narrow scope of the declaration subjects, insufficient objects of the declaration, limited transparency to the society, we can't deny the great breakthrough of it because this is the first step for our country to explore the institutionalization of properties declaration system. This regulation standardizes income of leading cadres and makes the properties declaration has laws to abide by. This was a preliminary attempt to establish civil servants' properties declaration system, and it laid a solid foundation for properties declaration system with Chinese characteristics. In 2001, the Party's Central Commission for Discipline Inspection and the CPC's Organization Department jointly issued policy document "Report of the Family Properties of Provincial Present Leading Cadres ( the Tentative Version)" (hereinafter referred to as the Family Properties Declaration Provisions). However, it's just a policy document with less than 600 words other than law. Due to the legal status of the policy documents is not clear in China nowadays, the authority and credibility of this provision was discounted, so that its compelling force was greatly reduced. In addition, there were no specific procedures that could be carried out to guarantee its effective implementation.

From local government level, practical explorations of civil servants' properties declaration system was made in Altay and Cixi in 2008, and it attracted the attention of central government. On May25, 2008, Altay Commission for Discipline Inspection issued Regulations of Properties Declaration of Country-level Leading Cadres (the Tentative Version), and required all country-level 
leading cadres declared their properties based on the provision. It was hailed by the media as a pioneering work. The effective implementation of the civil servants' properties declaration system in Altay region showed the feasibility of the system in the whole country. It is clearly that even such a impoverished area could implement the civil service properties declaration system, not to mention other developed places. In addition, Lichuan in Jiangxi Province and Huaian in Jiangsu Province also carried on the reform of the properties declaration system. From the northwest to the vast inland and coastal regions, properties declaration system gradually spread throughout in China. These explorations on regional properties declaration system provided valuable experiences to the establishment of civil servants' properties declaration system in China. Although there are still a lot of problems such as lacking legal system and limited experiences in practice, the explorations of the system has never been stopped. The society needs more determination and motivation on the establishment and development of the properties declaration system.

\subsection{Practice of the status quo}

In view of the practices, the civil service properties declaration system is faced with enormous resistances.

There are opposite viewpoints on the implementation of Civil Servants' Properties Declaration System in China. The first is the theory of privacy: some people believe that civil servants' personal privacy also should be protected because these officials are also citizens just like ordinary people. if officials' properties were forced to publish, their right of privacy, would be violated. This is also the conflict between civil servant's 'right of privacy' and citizen's 'right to know'. People with vested interests bring more enormous resistances for the implementation of civil service property declaration system. "When some of our reforms involve in the special interests of some officials, who hold the power of making policy and leading policies direction, solving the relevant problems and performing the related reforms will become difficult." [2]

There still exit defects and loopholes in the properties declaration system in practice. Firstly, the range of application subject is relatively narrow. Implementing personal income declaration only aim at the county-level and bureau-level cadres nowadays: properties declaration of bureau-level cadres and incomes declaration of county-level cadres. Secondly, the scope of declaration objects is not very comprehensive. Without non-labor income, it only includes individual labor income. However, income does not represent property, it cannot objectively reflects the personal economic conditions of leading cadres; Thirdly, censorships lack of authority and independence. As an accepting institution of income declaration, the personnel department is convenient, flexible and direct. But the personnel department and the organization department don't have independent supervisory functions so that their impartiality, independence and authority are skeptical by society. Fourthly, over-light duty for the application subject when they break the rule. For example, the punishments for violators are light: only disciplinary sanctions, no administrative punishments or criminal penalties. In addition, there are no detailed regulations of punishments for different situations.

\section{The way of Breaking Through the Dilemma}

\subsection{Foreign system models of civil servants' properties declaration}

It is obviously that we can study successful system models from other developed countries to make up for the defects and the insufficiency which exist in Chinese civil servants' properties declaration system.

British civil servants mainly include senators and ordinary civil servants. British members of Parliament need declare all of their economic benefits to the society based on the system of income disclosure, including wages, bonuses, benefits as well as incomes of consulting, writing, speech and so on. According to the relevant government regulations, secretaries must report if the value of received gifts were more than 140 pounds and they can choose to buy the gifts by themselves.[3] The properties declaration system of the United States has two obvious characteristics: first, the system has a strong early-warning and great deterrent effect on civil servants; second, the system has penalty function for corruption and bribe, illegal incomes can be taken as a basis for the prosecution of civil 
servants even evidences of corruption and bribe are lacked. The American Government Moral Laws stipulated severe punishments of illegal behaviors in the properties declaration. People who refused to declare the assets, report it untruthfully, or delay to declare it will be reviewed strictly, and be punished directly. For the punishments of public servants who have illegally acquired properties, methods include depriving of illegal properties, returning the properties of the illegal obtained, resignation, and being penalized by the law of corruption and bribery, etc. [4]

\subsection{Concrete measures of establish and improve the civil service property declaration system}

The experiences of civil servants' properties declaration system in Britain and America have very important reference value for us.

Firstly, it's absolutely essential to establish the system of properties declaration and promulgate the 'Law of Civil Servants' Properties Declaration' as soon as possible. Legal effect and authority of the system should be improved through improve its legal status from policy documents up to the laws or administrative rules. Furthermore, the system must make society supervise civil servants in an easy way.

Secondly, it is imperative to expand the scope of declaration subject. All state functionaries should be brought into the scope, and in order to realize the comprehensive supervision, the following persons also should be included: (1) leading cadres at or above the county level who work in the party organs, National People's Congress organs, Chinese People's Political Consultative Conference organs, administrative departments, social organizations, and state-owned enterprises; (2) judges and prosecutors who work in People's Procuratorate and People's Court at all levels; (3) civil servants who work in public security organs, financial organs, industrial and commercial authorities, tax authorities and customs authorities at all levels. [5] Only by this way can we promote the improvement of the civil servants' properties declaration system effectively.

Thirdly, a reasonable scope of the declaration object should be defined. Scope of the declaration objects in the current properties declaration system is too narrow, which is not beneficial to have detailed understanding of state functionaries' true financial conditions. All properties of civil servants should be prescribed into the scope, which including: (1) real estate; (2) vehicles; (3) deposits, securities and other valuables if values are above a certain level (include gold and silver utensils, jewelry, antiques, famous paintings, etc.); (4) credits and debts, income of investment, income of management and contingent income if values are above a certain level; (5)salary; (6) intellectual properties and other service revenues; (7) personal and family expenditures if values are above a certain level; (8) securities, shares and other assets; (9) other properties which should be declared. [6]

Last but not the least, without independent and authoritative censorships, the law will not be able to execute. At present, censorships of income declaration are mainly personnel departments of individual organizations in China, which lack of independence and authority. It is essential to set up new and specialized censorships of income declaration. The methods of legal responsibilities should include administrative liability, civil liability and criminal liability, as well as intensifying legal sanctions. We can reference foreign practices and add the property crime of state functionaries in laws to punish civil servants who refuse to declare or declare untruthfully. It is necessary to enhance rigidity of properties declaration system, only if properties declaration can be carried out smoothly, can our country curb corruption effectively.

\section{Conclusion}

The civil servants' properties declaration system has been gradually recognized and carried out in China. In order to curb corruption more effectively, the system should be further investigated. Our government should take effort to establish and improve civil servants' properties declaration system which is suitable for China, enact related laws of properties declaration system and enhance rigidity of the system. This will greatly improve our ability to curb corruption. It is of great significance for China to promote the socialism legal construction, improve the credibility of the party and governments and build a harmonious socialist society. 


\section{References}

[1] Montesquieu. On the Spirit of Law[M]. Beijing: Business Press, 1961:154 (In Chinese)

[2] Wang Yukai. Deepening the Reform Should Involve Vested Interests: Thoughts About Establishing Civil Servants' Properties Declaration System[J]. Journal of the Central Party School, 2009,02:72-74 (In Chinese)

[3] Ye Guiyan. Theory of the Civil Servants' Properties Declaration System[J]. Theoretical Fields, 2006(11) (In Chinese)

[4] Li Mengyi. The Construction of Civil Servants' Properties Declaration System in China[D]. Lanzhou University, 2009 (In Chinese)

[5] Wang Minggao, Sun Changjun. Establishing and Improving the Family Properties Declaration System is an Important Move of Supervising the Leaders[J]. The Contemporary Construction of Chinese Communist Party, 2000(10) (In Chinese)

[6] Wu Xindong. Research on the Civil Servants' Properties Declaration System in China[D]. Peking University, 2010 (In Chinese) 